\title{
Advertise all opportunities large and small
}

Jane Norman

In every organisation there are lots of "additional tasks" to be done over and above the "day job" that people carry out. Some additional tasks are more high profile, require more specialised skills, are more desirable and are better rewarded than others. Many have a specific title, with a set of associated responsibilities. Almost all provide opportunities for staff to develop their skill set, experience and curriculum vitae. And carrying out small roles successfully gives individuals the confidence and track record to move on to bigger roles.

Universities are good about equality of opportunity when appointing to a new post. There is a job description and person specification, an advert, and equality of opportunity of application (see Defining excellence and Gender balancing staff recruitment: attracting the right candidates). Such strategies should also be employed (even internally) for titular roles within institutions such as Programme Director or Accessibility Officer. Several Schools in the University already follow this process.

This recipe is for whoever is charged with assigning the roles.

\section{Ingredients}

- A role that needs to be performed.

- All the people who could undertake the role.
- A means of communication with all the people who could undertake the role.

- Time to think through what the role requires, and to consider all the applications.

\section{Method}

1. Decide what task needs to be done. This is usually obvious - e.g. course organiser. It might be useful to group tasks together. If the role is vacant, it is worth considering whether the task still needs to be done, and whether it needs to be done in the same way.

2. Decide what skills and experience are required for the role. The lion tamer probably needs to have some experience with big cats, but having been to Africa may not be essential, even if the previous incumbents have been.

3. Write the job role, and the essential and the desirable person specification, down. This takes a bit of time, and is often missed, but "I will recognise it when I see it" is not the best approach, and if the task is important, it's just lazy. (If the task is not important, why are you trying to find someone to do it? See step 1 above.) Factoring in the extra time to write out the job role and person specification is well worth it. 
4. Advertise the role. You may know just the person who would be great at this, but there may be others who would be even greater. Appointing without advertising (and considering all the applications) is a shortcut to implicit bias. The School of Divinity has taken the approach of emailing all academic staff to invite them to apply for internal roles. This may work well in other areas too.

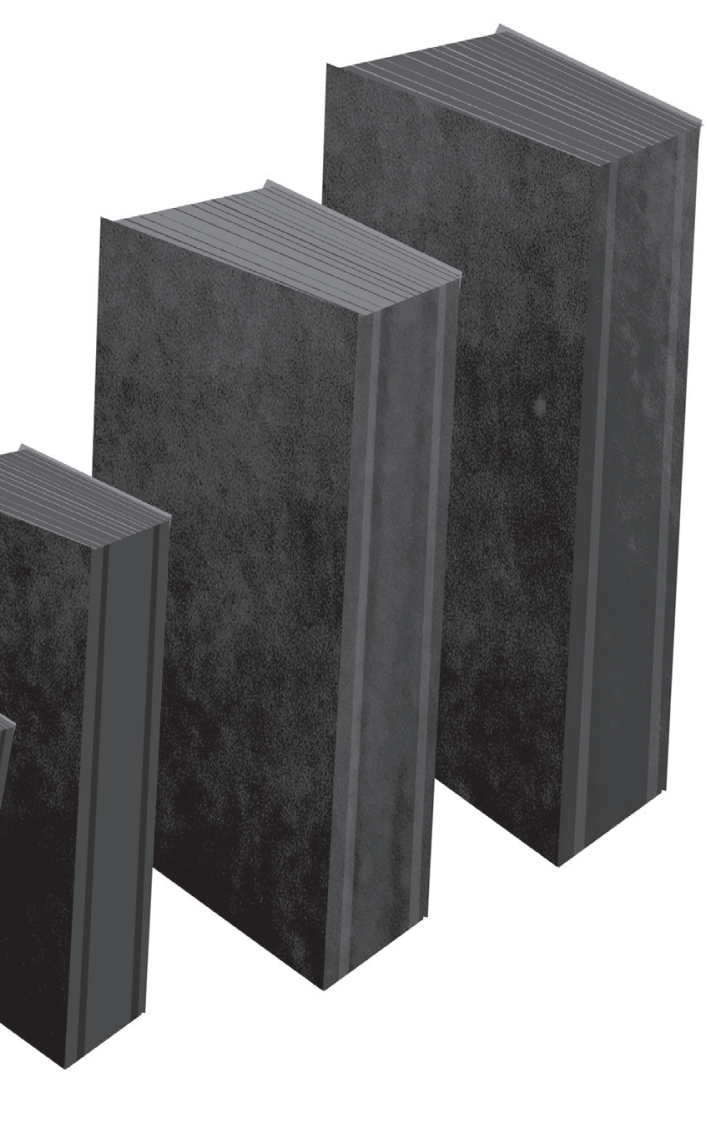


5. Encourage those who you think would be good at the role to apply. Sometimes people need a bit of a push. Even if they don't put themselves forward this time, they might next time. It is also worth highlighting upcoming opportunities to line managers to reach a wider pool of potential applicants. (See Raising your profile within your organisation.)

6. Consider all the applications. Have a predefined process for reviewing the applications. It doesn't need to be too heavyweight for smaller internal roles, but it does need to be systematic, fair, and involve more than just your own opinion. (See Unconscious bias.)

7. Be aware of workloads. If someone is taking on a significant additional task or role, you will need to review their overall workload to avoid placing staff under too much pressure.
8. Use this as a development opportunity for the near misses. Good talent management involves encouraging people to develop, and helping them to address gaps in their training or experience. Give feedback to the applicants who didn't make it this time, so that they can work with their line manager or PDR (Performance Development Review) reviewer to develop the skills they were missing. 